\title{
The Cost-Effectiveness of the Kiva Antibullying Program: Results from a Decision-Analytic Model
}

\author{
Mattias Persson ${ }^{1}$ D $\cdot$ Linn Wennberg ${ }^{2} \cdot$ Linda Beckman $^{3} \cdot$ Christina Salmivalli $^{4} \cdot$ Mikael Svensson $^{5}$
}

Published online: 4 May 2018

(C) The Author(s) 2018

\begin{abstract}
Bullying causes substantial suffering for children and adolescents. A number of bullying prevention programs have been advocated as effective methods for counteracting school bullying. However, there is a lack of economic evaluations of bullying prevention programs assessing the "value for money." The aim of this study was to assess the cost-effectiveness of the Finnish bullying prevention program KiVa in comparison to "status quo" (treatment as usual) in a Swedish elementary school setting (grades 1 to 9). The cost-effectiveness analysis was carried out using a payer perspective based on a Markov cohort model. The costs of the program were measured in Swedish kronor and Euros, and the benefits were measured using two different metrics: (1) the number of victim-free years and (2) the number of quality adjusted life years (QALYs). Data on costs, probability transitions, and health-related quality of life measures were retrieved from published literature. Deterministic and probabilistic sensitivity analyses were carried out to establish the uncertainty of the cost-effectiveness results. The base-case analysis indicated that KiVa leads to an increased cost of $€ 829$ for a gain of 0.47 victim-free years per student. In terms of the cost per gained QALY, the results indicated a base-case estimate of $€ 13,823$, which may be seen as cost-effective given that it is lower than the typically accepted threshold value in Swedish health policy of around $€ 50,000$. Further research is needed to confirm the conclusions of this study, especially regarding the treatment effects of KiVa in different school contexts.
\end{abstract}

Keywords Cost-effectiveness $\cdot \mathrm{KiVa} \cdot$ Bullying prevention program $\cdot$ Decision modeling

Bullying in schools, defined as repeated aggressive behavior including intentions to be hurtful or harmful and some sort of power imbalance between those involved, is a widespread public health problem (Eriksen et al. 2014; Olweus 1993; Ttofi and Farrington 2011).

Electronic supplementary material The online version of this article (https://doi.org/10.1007/s11121-018-0893-6) contains supplementary material, which is available to authorized users.

Mattias Persson

mattias.persson@oru.se

1 Department of Economics, School of Business, Örebro University, 70182 Orebro, Sweden

2 Department of Public Health \& Community Medicine, University of Gothenburg, Gothenburg, Sweden

3 Department of Public Health, Karlstad University, Karlstad, Sweden

4 Department of Psychology, University of Turku, Turku, Finland

5 Health Metrics, The Sahlgrenska Academy, University of Gothenburg, Gothenburg, Sweden
Bullying can be physical, relational, or verbal and occur "face-to-face" and online (cyber-bullying). Based on a study conducted in 33 European and North American countries, the lowest bullying prevalence rates were found in Sweden and England (3-5\%), while the highest rates were found in Lithuania and Belgium (17-29\%) (Chester et al. 2015).

Being a victim of bullying has been shown to increase the risk of both direct, and long-term mental health problems, such as psychosomatic problems, school satisfaction, social support, future optimism, and self-esteem, as well as worse educational and labor market outcomes (Gini and Pozzoli 2009; Smokowski et al. 2014; Takizawa et al. 2014). For example, a recent review on the long-term consequences of bullying showed a strong association between being a victim of bullying and later onset in life of depression, poor academic achievement, school absenteeism, and suicidal behavior (Wolke and Lereya 2015).

Most previous research studies on bullying prevention programs have focused on the effectiveness in reducing the prevalence of bullying but have neglected the cost-effectiveness. Hence, this study aims to address the knowledge gap 
regarding the cost-effectiveness of bullying prevention programs and specifically to evaluate the cost-effectiveness of a wide spread bullying prevention program: the KiVa program.

As part of bullying prevention work, many schools have implemented manual-based bullying prevention programs. Results from a meta-analysis on manual-based bullying prevention programs showed that some (but far from all) programs show evidence of being effective, with an average reduction in bullying prevalence of about $20 \%$ (Ttofi and Farrington 2011). However, studies also show that a substantial proportion of the programs lack any beneficial effect and many schools also implement programs where there are no research studies or data on effectiveness at all (Evans et al. 2014; Ferguson et al. 2007; Flygare et al. 2013; Merrell et al. 2008).

A relatively new program that has gained increasing attention is "KiVa" (Salmivalli et al. 1998), which has been evaluated in a number of randomized experiments with promising results in terms of reducing the prevalence of bullying (Kärnä et al. 2013; Kärnä et al. 2011a, b).

As with any public health program (or investment/action in general), adopting a bullying prevention program comes with costs, both direct program costs and indirect costs. If a school implements a costly bullying prevention program, it may imply that funds for, e.g., teachers, facilities, and material, will be displaced. It is therefore essential to consider if a specific investment provides reasonable value for money. To the best of our knowledge, there are only two published economic evaluations of bullying prevention programs, both focusing on the historically popular Olweus Bullying Prevention Program (Beckman and Svensson 2015; Persson and Svensson 2013). Beckman and Svensson (2015) utilized a decision-tree model to evaluate the cost-effectiveness of the Olweus bullying prevention program implemented in grades 7 to 9 in a Swedish school context. The results indicated that the Olweus Bullying Prevention Program is moderately cost-effective. And in Persson and Svensson (2013), the Olweus Bullying Prevention program is used as an example to showcase how to conduct an economic evaluation of bullying prevention programs. The results indicated that it is motivated to implement the Olweus Bullying Prevention program compared to no specific program at all ("status quo").

The aim of this study was to address the knowledge gap regarding the cost-effectiveness of bullying prevention programs and specifically to evaluate the cost-effectiveness of the KiVa program. We developed a decision-analytic model in the form of a Markov cohort model to assess the cost-effectiveness of the KiVa program in comparison to status quo (i.e., "treatment as usual"). The results can thus be interpreted as the expected value of the costeffectiveness for an elementary school, grades 1 to 9 in a Swedish context, moving from the typical/average bullying prevention work to implementing the manual-based
KiVa program in a whole-school approach with all its components.

\section{The KiVa Program}

KiVa (acronym for the Finnish term of "against bullying") was developed in 2006 at the University of Turku in Finland for students between the ages 7 to 15 years (Salmivalli et al. 2011). The development of the program was initiated by the Finnish government and conducted in collaboration between the Department of Psychology and the Center for Learning Research at the University of Turku (Kärnä et al. 2011a). The goals of KiVa are to reduce the prevalence of bullying, counteract new bully-victim relationships, and reduce the negative consequences of bullying. The program takes a wholeschool approach, which implies that it requires commitment and engagement from staff, students, and their parents. Consequently, $\mathrm{KiVa}$ is meant to be a part of everyday antibullying efforts and not implemented as a temporary project (Salmivalli et al. 2013). The KiVa program has three different versions adjusted for ages/grades (ages 7-9, 10-12, and 13-15 years) and is composed of two types of activities: universal actions and indicated actions (see Fig. 1).

The universal actions mainly consist of student lessons (primary school), themes (secondary school), and virtual learning environments. The manual-based student lessons are held by a classroom teacher and contain ten double lessons that cover a variety of topics, such as mechanisms of bullying, forms of bullying, group pressure, strategies to end ongoing bullying, and ways to support the victim. Students learn by discussions, group work, role-play exercises, and videos (Salmivalli et al. 2013). The themes are similar and are introduced to students in lessons, theme days, or at similar occasions (Kärnä et al. 2011a). The universal actions also include computer games (younger ages) and an online environment called "KiVa Street" (older ages). Furthermore, the school is equipped with KiVa symbols (e.g., posters and vests), with the intention of reminding students and staff of their work against bullying. Parents also receive a guide about bullying and ways to identify and prevent bullying (Haataja et al. 2014). The indicated actions refer to the management of acute cases of bullying and are carried out by a KiVa team of three teachers or other school staff in the form of individual and/or group discussions with the victim and the bully .

\section{Method and Material}

\section{Cost-Effectiveness Analysis}

Cost-effectiveness analysis (CEA) is a method of economic evaluation that compares differences in costs to differences 
Fig. 1 Universal and Indicated Action Components of the KiVa Program

\begin{tabular}{|c|c|c|}
\hline \multicolumn{3}{|c|}{ The KiVa Program } \\
\hline \multicolumn{3}{|c|}{$\frac{\text { Universal Actions }}{\text { Actions directed at the school and class level }}$} \\
\hline & Student Lessons in Grade $1,4 \& 7$ & Parental Guide \\
\hline \multirow{3}{*}{\multicolumn{2}{|c|}{$\begin{array}{l}\text { Focus on the mechanisms and consequences of } \\
\text { bullying, as well different forms of bullying. } \\
\text { These lessons also focus on what the students } \\
\text { themselves can do together to counter bullying } \\
\text { and support their victimized peers. In Grade 7, } \\
\text { the lessons could instead be implemented as } \\
\text { theme days around four themes. }\end{array}$}} & $\begin{array}{l}\text { Information materials about } \mathrm{KiVa} \\
\text { program directed to parents. }\end{array}$ \\
\hline & & Web Resources \\
\hline & & $\begin{array}{l}\text { Resources for school staff about } \\
\text { the KiVa program. }\end{array}$ \\
\hline & Virtual Learning Environment & Posters and Vests \\
\hline & $\begin{array}{l}\text { This is closely related to the lessons and themes, } \\
\text { to enhance the learning process. Computer } \\
\text { games in grade } 1 \text { and } 4 \text {, and an online environ- } \\
\text { ment in grade } 7\end{array}$ & $\begin{array}{l}\text { These materials should be re- } \\
\text { minding students and school staff } \\
\text { about their work with the KiVa } \\
\text { program. }\end{array}$ \\
\hline \multicolumn{3}{|c|}{$\begin{array}{l}\text { Indicated Actions } \\
\text { Actions directed to handle specific cases of bullying }\end{array}$} \\
\hline & $\underline{\text { KiVa Team }}$ & $\underline{\text { Posters and Vests }}$ \\
\hline & $\begin{array}{l}\text { Team of three teachers or other school } \\
\text { staff, take action with individual or group } \\
\text { discussion with bullies and victim. These } \\
\text { discussion meetings are systematically } \\
\text { followed up with meetings of the bullies } \\
\text { and victims. }\end{array}$ & $\begin{array}{l}\text { Classroom teacher meets with a } \\
\text { few students in the class to en- } \\
\text { courage them to support the } \\
\text { victimized student. }\end{array}$ \\
\hline
\end{tabular}

Source: Kärnä et al. 2011a, Salmivalli et al. 2013, Haataja et al. 2014. in benefits between two (or more) programs/treatments. CEA is increasingly used as a tool to inform decision makers on the "value for money" in prioritization between alternative programs and investments (ISPOR 2013). CEA with an "utility-based" outcome measure is also referred to as cost-utility analysis (CUA), but we use the generic term of CEA throughout this paper.

The result in a CEA is typically presented as an incremental cost-effectiveness ratio (ICER). In our setting, the ICER will show the difference in cost divided by the difference in effectiveness of adopting KiVa compared to status quo (SQ). The ICER is calculated as follows: $\left(\right.$ Cost $_{\mathrm{KiVa}}{ }^{-}$ Cost $\left._{\mathrm{SQ}}\right) /\left(\right.$ Effectiveness $_{\mathrm{KiVa}}-$ EffectivenesS $\left._{\mathrm{SQ}}\right)$. The ICER can be interpreted as the price/cost to gain one additional unit of the effectiveness measure. Thus, the lower the ICER the more cost-effective is the evaluated program (in relation to the comparator). In our analysis, we calculated the ICER using two different measures of effectiveness: the number of victim-free years and the number of quality adjusted life years (QALYs).

A CEA can be conducted alongside (randomized) controlled experiments and thus be based on primary data collection of individual-level costs and benefits. But, it is also common to conduct a CEA in the form of decision analytic models, where data on costs and benefits are based on secondary data (e.g., from reviews or administrative sources). Decision makers must decide on implementation (or no implementation) on a large range of programs and treatments where we lack primary data from randomized studies, thus creating a great need for decision-analytic modeling studies in the absence of large randomized studies.

\section{The Modeling Approach: a Markov Cohort Model}

The simplest modeling approach to conduct a CEA is to set up a decision-tree that represents the possible decision(s) and the associated consequences with each decision. However, in contexts where a program has consequences over several years, it quickly becomes cumbersome to represent the model using a decision-tree. An alternative modeling approach is to construct a Markov cohort model (state-transition model), which easily deals with recurring events over a longer time period (Caro et al. 2012). A Markov model consists of mutually exclusive states, where a certain share of the cohort transitions 
between states over time, where costs and effectiveness outcomes are assigned to each state (Briggs et al. 2006).

In our context, the two exclusive states were "bullied" and "not bullied." For each cohort entering the school, there were different probabilities assigned for transitioning into a bullied or non-bullied state. Furthermore, between each grade, it was possible to stay in the current state or transition to the other state. Hence, a student could transition from bullied to not bullied one cycle (grade year) and move back to bullied at a later cycle. Figure S1 in the Online Supplement shows a simple graphical representation of the model. The model is run for each intervention arm, i.e., the KiVa-arm and the status quoarm, and results from both runs were used to calculate the ICER of KiVa vs. status quo.

\section{The Policy and Model Context}

The target population for the model was an average cohort of students in a Swedish elementary school where children enter the first grade at age 6/7 years and graduate in grade nine at age 15/16 years (Swedish National Agency for Education 2006). We assumed a cohort size of 75 students divided in 3 classes, which is in line with average data for a Swedish school. Sensitivity analyses were carried out varying these assumptions.

The decision-model takes a "payer" perspective, which in the Swedish policy context implies a municipality context. Elementary schools in Sweden are funded by each municipality (in total there are 290 municipalities in Sweden), and decisions about implementing specific programs, such as the KiVa program, are taken at the municipality and/or school level. This implies that the costs included in the evaluation are costs borne by the school and municipality, i.e., direct costs to implement the program and the teacher and school staff resources that will be directed into the program.

The model followed a cohort of school entry students (grade 1) until graduation (grade 9). When performing economic evaluations, it is generally advised to take into account the timing of costs and effects using a social discount rate, which entails that future consequences are valued less than present consequences (Briggs et al. 2006). Costs and effectiveness outcomes were thus discounted at the point in time they occurred, with the rate of $3 \%$, which is the recommended social discount rate in Sweden for health economic evaluations and in line with international recommendations (Siegel et al. 1996; TLV 2003). Costs were measured in the price level of 2017. Cost data in Euros were adjusted to Swedish kronor $(€ 1=9.5 \mathrm{SEK})$.

To measure the effectiveness of KiVa we considered two different metrics. The first metric was the number of victimfree years of bullying. The primary objective of a bullying prevention program is to reduce the prevalence of bullying, and we thus evaluated the KiVa program in terms of if and how many victim-free school years it provides. A student that is never a victim of bullying will thus have nine victimfree years. The second effectiveness metric we considered was the Quality Adjusted Life Years (QALYs). QALY is a measure of health status in a single combined function, including length of life and quality of life (Pliskin et al. 1980; Zeckhauser and Shepard 1976). QALY weights can be between 0 and 1 (they may be negative as well, but not of relevance in this study), where 0 is interpreted as "equal to being dead" and 1 is interpreted as the best possible health state. Considering that bullying reduces health-related quality of life, a program that can reduce the prevalence of bullying will thus imply higher health-related quality of life and therefore more QALYs.

\section{Input Parameters}

Due to lack of relevant trial data on the full set of necessary costs and outcomes, which is often the case in health economic evaluations (Briggs et al. 2006), the input parameters for the Markov model consisted of secondary data gathered from the best available sources. The parameter estimates used in the model are summarized in Table 1 and further described below.

\section{Transition Probabilities}

The assumption was that for a cohort entering a school in the status quo situation, the initial prevalence of bullying was $4 \%$, as acquired from an extensive national Swedish survey (Currie et al. 2012). In order to assess the transitions between being bullied and not being bullied, we could identify one Swedish study with longitudinal data on bullying experience (at the individual level) from grade 1 to grade 9 (Beckman et al. 2016). We were able to use the primary data from that study to construct the annual transitions between bullied and not bullied states (see Table S2 in the Online Supplement for the transition probabilities used).

\section{Program Effect}

The data on the treatment effect of the KiVa program was estimated based on a systematic review (see Table S3 in the Online Supplement for the search strategy and results). We included studies that evaluated the KiVa program compared to status quo using randomized experiments. The odds ratios (ORs) of being bullied without KiVa compared to intervention schools with KiVa were found to range from 1.13 to 1.83 (Garandeau et al. 2014; Kärnä et al. 2011a, b; Williford et al. 2013; Yang and Salmivalli 2013). The weighted mean of the treatment effect of KiVa from these studies correspond to a relative risk of being bullied in a school with $\mathrm{KiVa}$ (compared to a status quo school) of 0.58 . 
Table 1 Markov model: input parameters for costs, program treatment effects, and quality of life

\begin{tabular}{|c|c|c|c|}
\hline Model parameter & Value (std.err/range) & Distribution & Reference \\
\hline \multicolumn{4}{|l|}{ Program effect } \\
\hline $\begin{array}{l}\text { KiVa treatment effect in terms } \\
\text { of relative risk reduction }\end{array}$ & $0.58(0.2)$ & Log-normal & $\begin{array}{l}\text { Garandeau et al. (2014); Kärnä et al. (2013); } \\
\text { Kärnä et al. (2011a, b); Williford et al. (2013); } \\
\text { Yang and Salmivalli (2013) }\end{array}$ \\
\hline \multicolumn{4}{|l|}{ Quality of life weight } \\
\hline Non-bullied student & $0.89(0.2)$ & Beta & Burström et al. (2001) \\
\hline Utility decrement bullied student & $0.06(0.06)$ & Log-normal & Beckman et al. (2016) \\
\hline \multicolumn{4}{|l|}{ Direct program costs } \\
\hline Training fee & 32,207 SEK & - & KiVa International, personal communication \\
\hline License fee grade 1 & 2131 SEK & - & KiVa International, personal communication \\
\hline License fee grades $2-9$ & 1421 SEK & & KiVa International, personal communication \\
\hline Teacher manuals & 2970 SEK & - & KiVa International, personal communication \\
\hline Parental guide (per student) & 62.5 SEK & - & KiVa International, personal communication \\
\hline Posters and vests (per class) & 446 SEK & - & KiVa International, personal communication \\
\hline \multicolumn{4}{|l|}{ Indirect program costs } \\
\hline Labor costs (incl. social fees) & $261 \mathrm{SEK} / \mathrm{h}$ & Gamma & Statistics Sweden. (2014) \\
\hline Teachers time training $(256 \mathrm{~h})$ & 66,903 SEK & Gamma & KiVa International, personal communication \\
\hline Student lessons grades 1 and $4(30 \mathrm{~h})$ & 7840 SEK & Gamma & Salmivalli et al. (2013) \\
\hline Themes, grade $7(12.5 \mathrm{~h})$ & 3267 SEK & Gamma & Salmivalli et al. (2013) \\
\hline \multicolumn{4}{|l|}{ General model parameters } \\
\hline Discount rate & $3 \%(0-5 \%)$ & - & TLV (2003) \\
\hline Classes per cohort & $3(1-5)$ & Uniform & Swedish National Agency for Education (2015) \\
\hline Cohort size (students in grade) & $75(25)$ & Normal & Swedish National Agency for Education (2015) \\
\hline
\end{tabular}

\section{Cost Data}

Cost data was retrieved from the suppliers and KiVa copyrightholder together with wage data from Swedish registers. The alternative to KiVa in the cost-effectiveness analysis was the status quo, which implies no change in current cost levels.

The program has a number of direct implementation costs including training and licensing fees, and per unit costs for teacher manuals, parental guides, and poster and vests. The indirect program costs consist of the time used to implement the program that will necessarily "crowd out" other school activities. These are monetized based on the time use (hours) multiplied by the teacher wage per hour (including social fees), which is what the municipalities actually pay for each hour of additional teacher time. The indirect program costs (time use) are larger than the direct implementation costs.

\section{Quality of Life Data}

As described in the "The Policy and Model Context" section, the effectiveness was measured in the number of victim-free years as well as in QALYs. We use the latter since this facilitates comparisons with other health and public health programs. In order to assess the total number of QALYs in each cohort, we had to assign health-related quality of life data for the two states. Students that are not bullied were assigned a health-related quality of life score of 0.89 (the "QALY weight"), based on data from a Swedish population survey (Burström et al. 2001). We were able to identify one study with estimates on the reduction in quality of life score due to being a victim of bullying (Beckman et al. 2016). The study used responses from 758 adolescents on the SF-6D survey to estimate health-related quality of life scores on the $0-1$ index. The average reduction was estimated at 0.06 (Brazier et al. 2002), and the health-related quality of life (QALY weight) of a bully victim was set to 0.83 .

\section{Uncertainty}

Uncertainty refers to presumptions in the model itself or to uncertainty regarding the input parameters. Both a deterministic (DSA) and a probabilistic sensitivity analysis (PSA) were carried out assessing parameter uncertainty (Briggs et al. 2006). In the DSA, one input parameter from the model was changed individually to investigate the impact on the ICER. This type of analysis clarifies what happens if one particular parameter alters, which can be used to identify critical parameters (Briggs et al. 2012). The PSA asses the uncertainty by jointly varying parameter inputs and in this case jointly changing the following parameters: transition probabilities, KiVa treatment effect, QALY weights, and costs of implementing KiVa (see Table 1 for the ranges and assumed distributions).

\section{Results}

\section{Base-Case Results}

Table 2 shows the base-case results as well as results from the deterministic sensitivity analysis (all results are expressed per 
Table 2 The cost-effectiveness of KiVa: base-case results and deterministic sensitivity analysis

\begin{tabular}{|c|c|c|c|c|c|}
\hline Approach & Cost (SEK) & QALYs & Victim-free years & $\begin{array}{l}\text { Cost per gained } \\
\text { QALY (SEK) }\end{array}$ & $\begin{array}{l}\text { Cost per victim- } \\
\text { free year (SEK) }\end{array}$ \\
\hline \multicolumn{6}{|c|}{ Base-case results } \\
\hline KiVa & 3686 & 6.91 & 8.59 & \multirow[t]{2}{*}{131,321} & \multirow[t]{2}{*}{7879} \\
\hline Status quo & 0 & 6.88 & 8.04 & & \\
\hline \multicolumn{6}{|c|}{ Deterministic sensitivity analysis } \\
\hline \multicolumn{6}{|c|}{ Years of implementation (base-case 9 years, grades 1-9) } \\
\hline 3 years & & & & 604,988 & 36,299 \\
\hline 6 years & & & & 203,696 & 12,222 \\
\hline \multicolumn{6}{|c|}{ Initial prevalence of bullying (base-case $4 \%$ ) } \\
\hline $2 \%$ & & & & 142,278 & 8537 \\
\hline $5 \%$ & & & & 126,452 & 7587 \\
\hline $7 \%$ & & & & 117,723 & 7063 \\
\hline $10 \%$ & & & & 106,676 & 6401 \\
\hline \multicolumn{6}{|c|}{ Cohort size (base-case 75 in 3 classes) } \\
\hline 65 & & & & 150,333 & 9020 \\
\hline 70 & & & & 140,148 & 8409 \\
\hline 80 & & & & 123,598 & 7416 \\
\hline 85 & & & & 116,783 & 7007 \\
\hline \multicolumn{6}{|c|}{ Relative risk reduction with KiVa (base-case RR 0.58) } \\
\hline 0.3 & & & & 86,699 & 5202 \\
\hline 0.5 & & & & 112,587 & 6755 \\
\hline 0.7 & & & & 179,664 & 10,780 \\
\hline \multicolumn{6}{|c|}{ Quality of life weight: difference in QALY weights bullied vs non-bullied (base-case - 0.06 QALY weight) } \\
\hline 0.03 & & & & 262,642 & 7879 \\
\hline 0.05 & & & & 157,585 & 7879 \\
\hline 0.07 & & & & 112,561 & 7879 \\
\hline 0.08 & & & & 98,491 & 7879 \\
\hline 0.10 & & & & 78,793 & 7879 \\
\hline \multicolumn{6}{|c|}{ Total cost of KiVa (base-case $3686 \mathrm{SEK} /$ student) } \\
\hline 3000 SEK & & & & 106,879 & 6413 \\
\hline 4000 SEK & & & & 142,506 & 8550 \\
\hline 6000 SEK & & & & 213,759 & 12,826 \\
\hline 9000 SEK & & & & 320,638 & 19,238 \\
\hline \multicolumn{6}{|c|}{ Discount rate (base-case 3\%) } \\
\hline $0 \%$ & & & & 116,037 & 6962 \\
\hline $1 \%$ & & & & 121,005 & 7260 \\
\hline $2 \%$ & & & & 126,100 & 7566 \\
\hline $4 \%$ & & & & 136,667 & 8200 \\
\hline $5 \%$ & & & & 142,137 & 8528 \\
\hline
\end{tabular}

student). The total discounted cost for the KiVa program over a time horizon of 9 years is 3686 SEK per student (€388). This should be interpreted as the additional cost per student (from the status quo) if implementing the KiVa program. The benefits show an increase of 0.47 victim-free years (from 8.04 to 8.59) and a gain in QALYs of 0.03 (from 6.88 to 6.91). The implied associated cost-effectiveness is as follows: cost per victim-free year 7879 SEK (€829) and cost per QALY 131,321 SEK (€13,823).

\section{Deterministic Sensitivity Analysis}

Table 2 also includes the results of the deterministic/univariate sensitivity analysis, in which we deterministically change the values of the parameters one at a time, both increasing and decreasing the value from the base-case.

Overall, the changes of the different parameters behaved as we expected in terms of the effect of the cost per victim free-year and cost per QALY. One important parameter, with a relatively large impact, was the number of years/grades over which $\mathrm{KiVa}$ is implemented. The base-case result assumed that the program is implemented and run over 9 years (i.e., starting in grade 1 and continuing up to grade 9). However, many Swedish schools are divided in such a way that they only have grades $1-6$ or grades 6/7-9, which makes it impossible to implement the program for 9 years in the same school. Assuming that $\mathrm{KiVa}$ is implemented over 3 years (grades 7-9) implied a cost per QALY of 604,988 SEK $(€ 63,683)$ and a cost per victim-free year of 36,229 SEK (€3814).

Another important variable is the relative risk reduction of the KiVa program, i.e., the effectiveness of the program in terms of reducing the prevalence of bullying. For instance, if the relative risk changes to 0.3 (from 0.58 ), the cost per QALY and cost per victim-free year decrease to 86,699 SEK (€9126) and 5202 SEK (€548). On the other 
hand, if KiVa is less effective than our base-case assumption and the relative risk would be 0.7 , the cost per gained QALY and cost per victim-free year increase to 179,664 SEK $(€ 18,912)$ and 10,780 SEK (€1135).

The discount rate, total cost of the program, cohort size, and initial bullying prevalence rates do not impact the cost-effectiveness by a large magnitude. Thus, the critical parameters seem to regard the effectiveness of the program, but primarily, the number of years over which $\mathrm{KiVa}$ is implemented.

\section{Probabilistic Sensitivity Analysis}

Figure 2 shows the cost-effectiveness plane based on 5000 Monte-Carlo simulations were all parameter estimates were changed jointly, i.e., each dot represents one specific ICER from each of the 5000 iterations. Almost all ICERs are in the north-east quadrant of the cost-effectiveness plane, which implies that the program is very likely to increase costs but also increase the number of QALYs.

Figure 3 shows the same underlying data represented in a cost-effectiveness acceptability curve, which shows the probability that KiVa is cost-effective given different willingness to pay per QALY thresholds (Briggs et al. 2006). The higher threshold value, the higher probability the intervention is costeffective. For the assumed Swedish informal threshold of 500,000 SEK per QALYs (€52,632/QALYs), the probability that KiVa is cost-effective is close to $100 \%$. At a threshold value of 100,000 SEK per QALY (€10,526) and 200,000 SEK per QALY ( $€ 21,053)$, the probability that KiVa is cost-effective is 68 and at $96 \%$, respectively.

\section{Discussion}

Being a victim of bullying causes significant suffering for children and adolescents (Takizawa et al. 2014). The importance of various bullying prevention programs has been acknowledged during the past decades, and numerous of them are run and implemented in schools. However, very few bullying prevention programs have strong evidence regarding effectiveness (Flygare et al. 2013), and there are more or less no evidence regarding the cost-effectiveness of bullying prevention programs.

In this study, we evaluated the cost-effectiveness of the KiVa bullying prevention program in the context of a Swedish elementary school. A Markov cohort model with a time frame of 9 years, or in other words over the full compulsory education in Sweden (grades 1 to 9), estimated the ICER at 131,321 SEK $(€ 13,823)$ per QALY. This estimate can be compared to the Swedish national threshold value for care programs, which states that a ratio below $500,000$ SEK ( $€ 52,632)$ per QALY can be considered moderately cost-effective (The National Board of Health and Welfare 2011). The results from the deterministic sensitivity analysis showed that the cost-effectiveness was substantially related to the number of grades/years for which the program was implemented. For example, in a school with only grades 7-9, which is relatively common in the Swedish school context, the cost per QALY was estimated at 605,000 SEK (€63,684), which is higher than the threshold value of 500,000 SEK $(€ 52,632)$. This highlights that the investment gives a substantially better cost-effectiveness if implemented over more grades, the primary reason that the implementation comes with some costs that are almost "fixed," which have to be
Fig. 2 Cost-effectiveness plane based on probabilistic sensitivity analysis (5000 iterations)

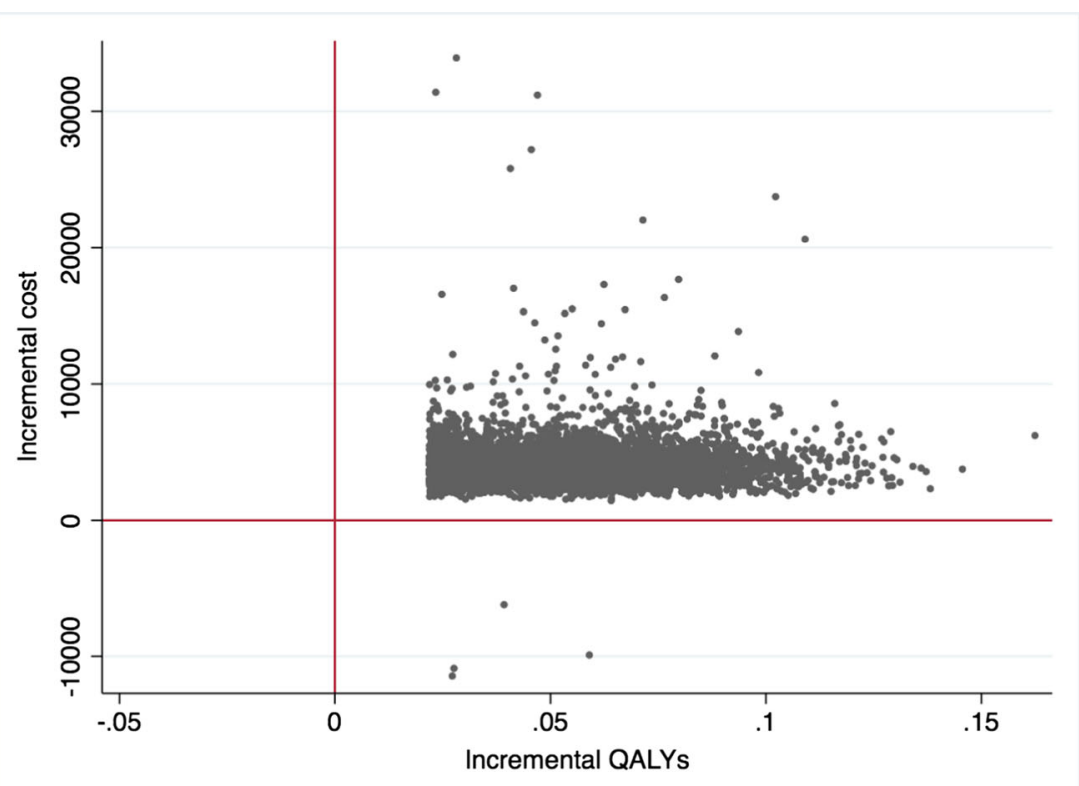


Fig. 3 Cost-effectiveness acceptability curve: the probability that KiVa is costeffective at different values per QALY

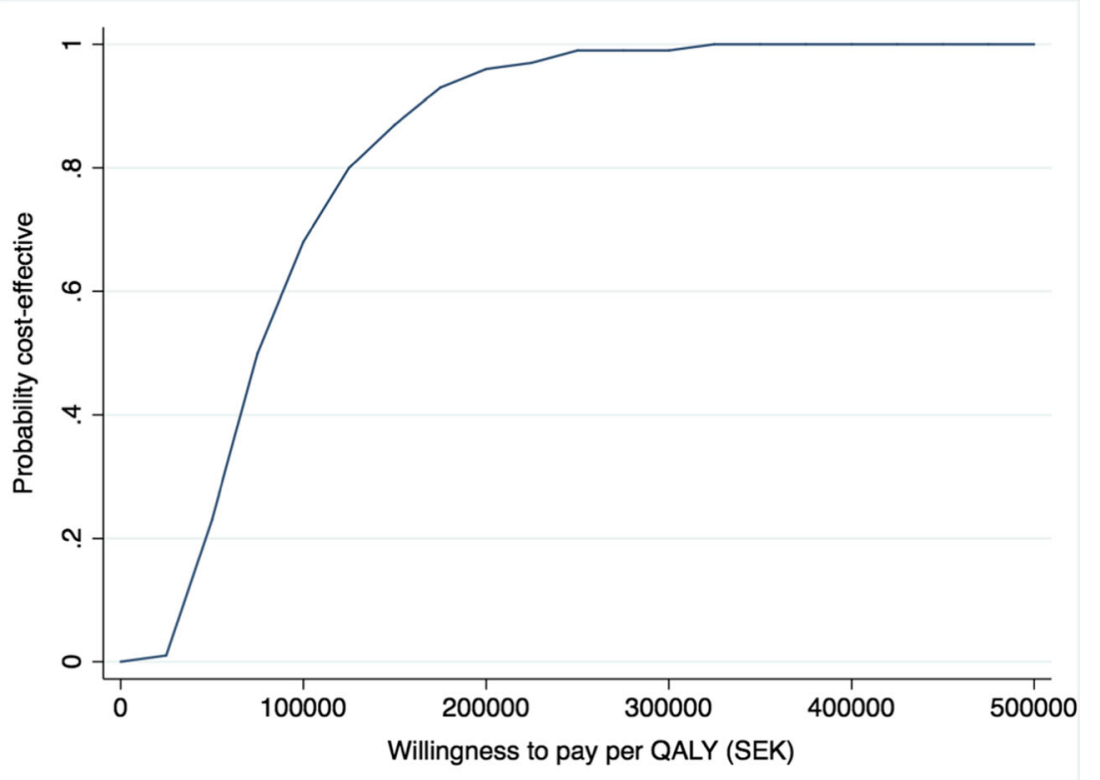

paid irrespective of the number of grades for which the program is implemented. The program therefore shows a better "return on investment" if implemented over as many grades as possible.

Compared to a recent study on the cost-effectiveness of the Olweus Bullying Program implemented in grades 7-9 (Beckman and Svensson 2015), the results here indicate that $\mathrm{KiVa}$ is more cost-effective. The cost-effectiveness of the Olweus Program showed a cost per victim-free year of 131,250 SEK $(€ 13,816)$, which can be compared to 12,222 SEK (€1287) with the KiVa program (or 36,299 SEK for a 3-year KiVa program). The cost per student of the two programs was fairly similar, which implies that the main reason for the better cost-effectiveness of the KiVa program is due to the evidence in favor of a higher effectiveness in terms of reducing the prevalence of bullying (Table 2). However, the two programs have not been compared "head-to-head," so all comparisons here rely on indirect comparisons, which implies that the different results should be interpreted with caution.

Transferability of the results as the basis for decision making to other settings is reliant on the suitability of the assumed parameter values (Table 1). For instance, in a country with a higher bullying prevalence than Sweden, the ICER would be slightly lower (i.e., KiVa would be more cost-effective). In a country with lower total costs of implementing KiVa, e.g., due to lower labor costs or larger classes (cohort size), also would imply a lower ICER.

Some important limitations need to be mentioned. To begin with, the evaluation was based on a modeling approach and the results are therefore dependent on the assumed parameter values as informed by secondary literature. Since KiVa is a relatively new program, limited research and data on the effectiveness of the program is currently available, and there is no evidence on the long-term effects of KiVa. Further, the effectiveness of KiVa may vary depending on degree of implementation fidelity, e.g., engagement and accuracy among those involved (Salmivalli et al. 2014), which implies that there is a need for further high-quality RCTs where KiVa is evaluated in different school contexts.

It is also a possibility that the estimated costs of the KiVa program was overestimated since the evaluation context compares KiVa to status quo (treatment as usual). Even if the typical school is not utilizing a formal manual-based program, there are most likely some activities and costs associated with the status quo activities. If implementing the KiVa program, these activities could be replaced by the KiVa program, and therefore, the incremental (additional cost) of the KiVa program would be lower than the explicit costs with the KiVa program as used in our model.

This study only considers the short-term costs and effects, as more long-term consequences of bullying are currently insufficiently explored to conduct a fair and realistic analysis (Takizawa et al. 2014). There are studies indicating that bullying causes continuing negative effects into adulthood (Sigurdson et al. 2015), but more knowledge is necessary to confirm such allegations. With more credible knowledge about potential long-term beneficial effects of preventing bullying, it may be that the cost-effectiveness of KiVa is underestimated.

\section{Conclusions}

The cost-effectiveness of the KiVa bullying prevention program was estimated to 7879 SEK ( $€ 829$ ) for each additional victim-free year gained and to 131,321 SEK $(€ 13,823)$ for 
each additional QALY gained. There is a lack of evidence on the effectiveness of bullying prevention programs, and assessing effectiveness and cost-effectiveness is therefore important to inform decision makers with fixed budget constraints. The results indicate that KiVa is cost-effective compared to the Swedish cost-effectiveness threshold value if implemented during 6 or 9 years (grades 1-6 or grades 1-9), but not cost-effective if only implemented in lower secondary school for 3 years (grades 7-9).

\section{Compliance with Ethical Standards}

Conflict of Interest One of the authors, Dr. Salmivalli, has been leading the team that has created and developed the KiVa program.

Ethical Approval All procedures performed in studies involving human participants were in accordance with the ethical standards of the national research committee and with the 1964 Helsinki declaration and its later amendments or comparable ethical standards.

Informed Consent Since this research is a modeling-based decision analytical study relying on non-sensitive secondary data and no individual level data has been utilized, formal consent is not required.

Open Access This article is distributed under the terms of the Creative Commons Attribution 4.0 International License (http:// creativecommons.org/licenses/by/4.0/), which permits unrestricted use, distribution, and reproduction in any medium, provided you give appropriate credit to the original author(s) and the source, provide a link to the Creative Commons license, and indicate if changes were made.

\section{References}

Beckman, L., \& Svensson, M. (2015). The cost-effectiveness of the Olweus bullying prevention program: Results from a modelling study. Journal of Adolescence, 45, 127-137. https://doi.org/10. 1016/j.adolescence.2015.07.020.

Beckman, L., Svensson, M., \& Frisén, A. (2016). Preference-based health-related quality of life among victims of bullying. Quality of Life Research, 25(2), 303-309. https://doi.org/10.1007/s11136-0151101-9.

Brazier, J., Roberts, J., \& Deverill, M. (2002). The estimation of a preference-based measure of health from the SF-36. Journal of Health Economics, 21(2), 271-292.

Briggs, A., Sculpher, M., \& Claxton, K. (2006). Decision modelling for health economic evaluation. Oxford: OUP.

Briggs, A., Weinstein, M. C., Fenwick, E. A., Karnon, J., Sculpher, M. J., \& Paltiel, A. D. (2012). Model parameter estimation and uncertainty analysis a report of the ISPOR-SMDM Modeling Good Research Practices Task Force Working Group-6. Medical Decision Making, 32(5), 722-732. https://doi.org/10.1177/0272989X12458348.

Burström, K., Johannesson, M., \& Diderichsen, F. (2001). Swedish population health-related quality of life results using the EQ-5D. Quality of Life Research, 10(7), 621-635. https://doi.org/10.1023/A: 1013171831202.

Caro, J. J., Briggs, A. H., Siebert, U., \& Kuntz, K. M. (2012). Modeling good research practices - Overivew: A report of the ISPOR-SMDM Modeling Good Research Practices Task Force-1. Value in Health, 15, 796-803.
Chester, K. L., Callaghan, M., Cosma, A., Donnelly, P., Craig, W., Walsh, S., \& Molcho, M. (2015). Cross-national time trends in bullying victimization in 33 countries among children aged 11,13 and 15 from 2002 to 2010. The European Journal of Public Health, 25(suppl 2), 61-64. https://doi.org/10.1093/eurpub/ckv029.

Currie, C., Zanotti, C., Morgan, A., Currie, D., de Looze, M., \& Roberts, C., Samdal, O., Smith, O., \& Barnekow, V. (2012). Social determinants of health 28 and well-being among young people. Health Behaviour in School-aged Children (HBSC) study: International report from the 2009/10 survey. Retrieved from http://www.euro. who.int/_data/assets/pdf_file/0003/163857/Social-determinantsof-health-and-well-being-among-young-people.pdf. Accessed 10 Oct 2016.

Eriksen, T. L. M., Nielsen, H. S., \& Simonsen, M. (2014). Bullying in elementary school. Journal of Human Resources, 49(4), 839-871.

Evans, C. B. R., Fraser, M. W., \& Cotter, K. L. (2014). The effectiveness of school-based bullying prevention programs: A systematic review. Aggression and Violent Behavior, 19(5), 532-544. https://doi.org/ 10.1016/j.avb.2014.07.004.

Ferguson, C. J., Miguel, C. S., Kilburn, J. C., \& Sanchez, P. (2007). The effectiveness of school-based anti-bullying programs: A metaanalytic review. Criminal Justice Review, 32(4), 401-414. https:// doi.org/10.1177/0734016807311712.

Flygare, E., Gill, P. E., \& Johansson, B. (2013). Lessons from a concurrent evaluation of eight antibullying programs used in Sweden. American Journal of Evaluation, 34(2), 170-189. https://doi.org/ 10.1177/1098214012471886.

Garandeau, C. F., Lee, I. A., \& Salmivalli, C. (2014). Differential effects of the KiVa anti-bullying program on popular and unpopular bullies. Journal of Applied Developmental Psychology, 35(1), 44-50.

Gini, G., \& Pozzoli, T. (2009). Association between bullying and psychosomatic problems: A meta-analysis. Pediatrics, 123(3), 6. https://doi.org/10.1542/peds.2008-1215.

Haataja, A., Voeten, M., Boulton, A. J., Ahtola, A., Poskiparta, E., \& Salmivalli, C. (2014). The KiVa antibullying curriculum and outcome: Does fidelity matter? Journal of School Psychology, 52(5), 479-493.

ISPOR. (2013). International Society for Pharmacoeconomics and Outcomes Research: Pharmacoeconomic guidelines around the world. Available at: http://www.ispor.org/peguidelines/index.asp. https://doi.org/10.1309/LMJ2J52MPMFSHDGX.

Kärnä, A., Voeten, M., Little, T., Poskiparta, E., Alanen, E., \& Salmivalli, C. (2011a). Going to scale: A nonrandomized nationwide trial of the $\mathrm{KiVa}$ antibullying program for grades 1-9. Journal of Consulting and Clinical Psychology, 79(6), 796.

Kärnä, A., Voeten, M., Little, T., Poskiparta, E., Kaljonen, A., \& Salmivalli, C. (2011b). A large-scale evaluation of the KiVa antibullying program: Grades 4-6. Child Development, 82(1), 311-330. https://doi.org/10.1111/j.1467-8624.2010.01557.x.

Kärnä, A., Voeten, M., Little, T., Alanen, E., Poskiparta, E., \& Salmivalli, C. (2013). Effectiveness of the KiVa antibullying program: Grades 1-3 and 7-9. Journal of Educational Psychology, 105(2), 535. https://doi.org/10.1037/a0030417.

Merrell, K. W., Gueldner, B. A., Ross, S. W., \& Isava, D. M. (2008). How effective are school bullying intervention programs? A metaanalysis of intervention research. School Psychology Quarterly, 23(1), 26-42. https://doi.org/10.1037/1045-3830.23.1.26.

Olweus, D. (1993). Bullying at school: What we know and what we can do. Oxford: Blackwell.

Persson, M., \& Svensson, M. (2013). The willingness to pay to reduce school bullying. Economics of Education Review, 35, 1-11. https:// doi.org/10.1016/j.econedurev.2013.02.004.

Pliskin, J. S., Shepard, D. S., \& Weinstein, M. C. (1980). Utility functions for life years and health status. Operations Research, 28(1), 206 224. https://doi.org/10.1287/opre.28.1.206. 
Salmivalli, C., Lagerspetz, K., Björkqvist, K., Österman, K., \& Kaukiainen, A. (1998). Bullying as a group process: Participant roles and their relations to social status within the group. Aggressive Behavior, 22(1), 1-15. https://doi.org/10.1002/(SICI) 1098-2337(1996)22:1<1::AID-AB1>3.0.CO;2-T.

Salmivalli, C., Kärnä, A., \& Poskiparta, E. (2011). Counteracting bullying in Finland: The KiVa program and its effects on different forms of being bullied. International Journal of Behavioral Development, 35(5), 405-411.

Salmivalli, C., Poskiparta, E., Ahtola, A., \& Haataja, A. (2013). The implementation and effectiveness of the KiVa antibullying program in Finland. European Psychologist, 18(2), 79-88. https://doi.org/10. 1027/1016-9040/a000140.

Salmivalli, C., Boulton, A. J., Poskiparta, E. H., Haataja, A., Voeten, M. J. M., \& Ahtola, A. (2014). The KiVa antibullying curriculum and outcome: Does fidelity matter? Journal of School Psychology, 52(5), 479-493. https://doi.org/10.1016/j.jsp.2014.07.001.

Siegel, J. E., Weinstein, M. C., Russell, L. B., \& Gold, M. R. (1996). Recommendations for reporting cost-effectiveness analyses. JAMA, 276(16), 1339-1341. https://doi.org/10.1001/jama.1996. 03540160061034 .

Sigurdson, J. F., Undheim, A. M., Wallander, J. L., Lydersen, S., \& Sund, A. M. (2015). The long-term effects of being bullied or a bully in adolescence on externalizing and internalizing mental health problems in adulthood. Child and Adolescent Psychiatry and Mental Health, 9(1), 1.

Smokowski, P. R., Evans, C. B. R., \& Cotter, K. L. (2014). The differential impact of episodic, chronic, and cumulative physical bullying and cyberbullying: The effects of victimization on the school experiences, social support, and mental health of rural adolescents. Violence and Victims, 29(6), 1029-1046. https://doi.org/10.1891/ 0886-6708.VV-D-13-00076.

Statistics Sweden. (2014). Average salary for teachers in elementary school. Retrieved from https://www.scb.se/sv_Hitta-statistik/ Temaomraden/Jamstalldhet/Fordjupningar/Uttbildning-ochforskning/Larare-och-skolledare/Genomsnittlig-lon-for-larare-igrundskolan/\#. Accessed 10 Oct 2016.

Swedish National Agency for Education. (2006). Curriculum for the compulsory school system, the pre-school class and the leisuretime centre Lpo 94. Retrieved from https://www.skolverket.se/ regelverk/skolfs/skolfs?_xurl_=http $\% 3 \mathrm{~A} \% 2 \mathrm{~F} \% 2 \mathrm{Fwww} 5$. skolverket.se $\% 2$ Fwtpub $\% 2$ Fws $\% 2$ Fskolfs $\% 2$ Fwpubext $\% 2 \mathrm{Ffs} \%$ 2FRecord\%3Fk\%3D258. Accessed 11 Oct 2016.

Swedish National Agency for Education. (2015). Schools and students compulsory school academic year 2015/16. Retrieved from https:/ www.skolverket.se/statistik-och-utvardering/statistik-i-tabeller/ grundskola/skolor-och-elever. Accessed 10 Oct 2016.

Takizawa, R., Maughan, B., \& Arseneault, L. (2014). Adult health outcomes of childhood bullying victimization: Evidence from a fivedecade longitudinal British birth cohort. American Journal of Psychiatry. https://doi.org/10.1176/appi.ajp.2014.13101401.

The National Board of Health and Welfare. (2011). Nationella riktlinjer för sjukdomsförebyggande metoder 2011-Hälsoekonomiskt underlag. Retrieved from http://www.socialstyrelsen.se/ nationellariktlinjerforsjukdomsforebyggandemetoder/Documents/ nr-sjukdomsforebyggande-halsoekonomisktunderlag.pdf. Accessed 11 Oct 2016.

TLV. (2003). Läkemedelsförmånsnämndens allmänna råd om ekonomiska utvärderingar. Retrieved from https://www.tlv.se/ download/18.467926b615d084471ac3396a/1510316400272/LAGlfnar-2003-2.pdf. Accessed 10 Oct 2016.

Ttofi, M. M., \& Farrington, D. P. (2011). Effectiveness of school-based programs to reduce bullying: A systematic and meta-analytic review. Journal of Experimental Criminology, 7(1), 27-56. https:// doi.org/10.1007/s11292-010-9109-1.

Williford, A., Elledge, L. C., Boulton, A., Depaolis, K., Little, T., \& Salmivalli, C. (2013). Effects of the KiVa antibullying program on cyberbullying and cybervictimization frequency among Finnish youth. Journal of Clinical Child and Adolescent Psychology, 42(6), 820-833.

Wolke, D., \& Lereya, S. T. (2015). Long-term effects of bullying. BMJ. https://doi.org/10.1136/archdischild-2015-309491.

Yang, A., \& Salmivalli, C. (2013). Different forms of bullying and victimization: Bully-victims versus bullies and victims. European Journal of Developmental Psychology, 10(6), 723-738. https://doi. org/10.1080/17405629.2013.793596.

Zeckhauser, R., \& Shepard, D. (1976). Where now for saving lives? Law and Contemporary Problems, 40(4), 5-45. https://doi.org/10.2307/ 1191310. 